RESEARCH PAPER

\title{
Current smoking and the risk of non-fatal myocardial infarction in the WHO MONICA Project populations
}

\author{
M S Mähönen, P McElduff, A J Dobson, K A Kuulasmaa, A E Evans, for the WHO MONICA \\ Project*
}

See end of article for authors' affiliations

.....................

Correspondence to: Markku Mähönen, MD, Department of Epidemiology and Health Promotion, KTL-National Public Health Institute, Mannerheimintie 166, FIN-00300 Helsinki,

Finland;

markku.mahonen.kłl.fi

Received 21 February 2003

Accepted 9 March 2004
Background: Cohort studies have shown that smoking has a substantial influence on coronary heart disease mortality in young people. Population based data on non-fatal events have been sparse, however. Objective: To study the impact of smoking on the risk of non-fatal acute myocardial infarction (MI) in young middle age people.

Methods: From 1985 to 1994 all non-fatal Ml events in the age group 35-64 were registered in men and women in the WHO MONICA (multinational monitoring of trends and determinants in cardiovascular disease) project populations (18 762 events in men and 4047 in women from 32 populations from 21 countries). In the same populations and age groups 65741 men and 66717 women participated in the surveys of risk factors (overall response rate $72 \%$ ). The relative risk of non-fatal Ml for current smokers was compared with non-smokers, by sex and five year age group.

Results: The prevalence of smoking in people aged 35-39 years who experienced non-fatal Ml events was $81 \%$ in men and $77 \%$ in women. It declined with increasing age to $45 \%$ in men aged $60-64$ years and $36 \%$ in women, respectively. In the 35-39 years age group the relative risk of non-fatal MI for smokers was $4.9(95 \%$ confidence interval (CI) 3.9 to 6.1$)$ in men and $5.3(95 \% \mathrm{Cl} 3.2$ to 8.7$)$ in women, and the population attributable fractions were $65 \%$ and $55 \%$, respectively.

Conclusions: During the study period more than half of the non-fatal Mls occurring in young middle age people can be attributed to smoking.
A lthough young people may acknowledge the well documented fact ${ }^{12}$ that cigarette smoking is a major risk factor for coronary heart disease (CHD) they (and even physicians) may think that this is only a concern in older age. But is this really true?

Several studies have shown acute deleterious effects of smoking on blood clotting, coronary vasomotor tone, and coronary endothelial function. ${ }^{3-6}$ Thus, in current smokers acute myocardial infarction (MI) may occur due to mechanisms other than coronary atherosclerosis and may suddenly affect a previously healthy heart. Also, there may be an interaction between smoking and hereditary coagulation defects such as the Leiden $\mathrm{V}$ mutation. ${ }^{7}$ These factors may explain why several studies have found a high prevalence of current smoking in young MI victims. ${ }^{8} 9$ There are, however, sparse population based data on smoking and MI in young people.

The World Health Organization established the MONICA (multinational monitoring of trends and determinants in cardiovascular disease) project to investigate trends and determinants of cardiovascular disease. ${ }^{10}$ From the mid 1980s to the mid 1990s, coronary events and acute coronary care were monitored in 32 populations in 21 countries for the age range 35-64 years. At least two CHD risk factor surveys were conducted on random samples of people in these populations during the same time period. To study the impact of smoking on the risk of MI in young people, we have used the MONICA survey data on smoking and contrasted them with the prevalence of smoking in MI patients in the MONICA populations.

\section{METHODS}

The methods of the MONICA project and main results have been published. ${ }^{11-14}$ Details of the methods, including population descriptions and the MONICA manual, are also available at the MONICA WWW pages (http://www.ktl.fi/ publications/monica/index.html). In short, the project involved monitoring coronary events, acute coronary care, and CHD risk factors over about 10 years among men and women aged 35-64 years who were residents of well defined geographical areas.

\section{Study populations}

Due to limited availability of data, the detailed composition of the study populations has varied for different MONICA publications. ${ }^{11-14}$ In this paper we have used the same 31 populations as in the paper by Tunstall-Pedoe and colleagues $^{14}$ with an additional population that did not have data spanning enough years for trend analyses to be included in that paper. The 32 study populations were mainly in Europe, but there was one in China, two in Australia, one in New Zealand, and two in North America. Descriptions of the populations and the data collection periods are shown in table 1 .

\section{Data collection}

All suspected coronary events in the study populations were monitored continuously from mid 1980s to mid 1990s. Nonfatal events and deaths were classified by standard diagnostic criteria as definite MI, possible MI, possible coronary death, unclassifiable death, or not MI. ${ }^{11}$

Acute coronary care (ACC) data, including smoking status, were collected as a separate data component, and linked to all

Abbreviations: $A C C$, acute coronary care; $C H D$, coronary heart disease; $\mathrm{Cl}$, confidence interval; ISIS, international studies of infarct survival; $\mathrm{Ml}$, myocardial infarction; MONICA, multinational monitoring of trends and determinants in cardiovascular disease: WHO, World Health Organization 
Table 1 MONICA populations and periods of data collection for each population

\begin{tabular}{|c|c|c|c|c|}
\hline Country & Population & $\begin{array}{l}\text { Mean population } \\
\text { aged } 35-64 \\
\text { years }(1000 \mathrm{~s})\end{array}$ & Periods of the risk factor surveys & $\begin{array}{l}\text { Comparison years for non-fatal definite } \\
\text { acute myocardial infarctions }\end{array}$ \\
\hline \multirow[t]{2}{*}{ Australia } & Newcastle & 148 & $5 / 83-12 / 83 ; 6 / 88-11 / 89,6 / 94-12 / 94$ & $85 ; 7 / 88-12 / 89 ; 93$ \\
\hline & Perth & 380 & $5 / 83-11 / 83 ; 6 / 89-12 / 89 ; 5 / 94-11 / 94$ & $84 ; 89 ; 93$ \\
\hline Belgium & Ghent/Charleroi & 162 & $2 / 85-7 / 87 ; 4 / 90-4 / 92$ & $9 / 86-7 / 87 ; 5 / 91-3 / 92$ \\
\hline Canada & Halifax & 108 & $9 / 85-11 / 88 ; 5 / 95-11 / 95$ & $85-88 ; 93$ \\
\hline China & Beijing & 288 & $9 / 84-11 / 85 ; 9 / 88-10 / 89 ; 9 / 93-10 / 93$ & $84-85 ; 88-89 ; 93$ \\
\hline Czech Republic & Czech Republic & 175 & $3 / 85-11 / 85 ; 3 / 92-12 / 92$ & $1 / 86-5 / 87 ; 1 / 91-11 / 91$ \\
\hline Denmark & Glostrup & 134 & $8 / 86-4 / 87 ; 2 / 91-3 / 92$ & $87 ; 91$ \\
\hline Finland & FINMONICA & 241 & $1 / 87-4 / 87 ; 1 / 92-3 / 92$ & $9 / 86-12 / 86 ; 9 / 92-12 / 92$ \\
\hline \multirow[t]{3}{*}{ France } & Lille & 340 & $6 / 86-2 / 89 ; 6 / 95-11 / 96$ & $10 / 86-6 / 87 ; 89 ; 94$ \\
\hline & Strasbourg & 32 & $1 / 85-8 / 87 ; 3 / 95-4 / 97$ & $85 ; 93$ \\
\hline & Toulouse & 322 & $5 / 85-2 / 87 ; 10 / 88-5 / 91 ; 12 / 94-7 / 96$ & $\begin{array}{l}86 ; 7 / 89-12 / 89 ; 90-91 \text { (odd months); 92; } \\
7 / 93-12 / 93\end{array}$ \\
\hline \multirow[t]{4}{*}{ Germany } & Augsburg & 217 & $10 / 84-5 / 85 ; 10 / 89-6 / 90 ; 10 / 94-7 / 95$ & $85 ; 89-90 ; 94$ \\
\hline & Bremen & 217 & $5 / 84-11 / 84 ; 5 / 88-11 / 88 ; 5 / 91-1 / 92$ & $85 ; 88 ; 91$ \\
\hline & East Germany & 46 & $1 / 88-11 / 88 ; 9 / 93-12 / 94$ & $89 ; 93$ \\
\hline & Rhein-Neckar & 233 & $9 / 83-7 / 87$ & $85 ; 88$ \\
\hline Iceland & Iceland & 75 & $6 / 83-11 / 83 ; 6 / 93-4 / 94$ & $1 / 82-9 / 83 ; 91-92$ \\
\hline \multirow[t]{2}{*}{ Italy } & Area Brianza & 345 & $4 / 86-3 / 87 ; 5 / 89-7 / 90 ; 9 / 93-11 / 94$ & $6 / 86-1 / 87 ; 89-90 ; 93-94$ \\
\hline & Friuli & 377 & $1 / 86-9 / 86 ; 3 / 89-12 / 89 ; 3 / 94-10 / 94$ & $86 ; 89 ; 93$ \\
\hline Lithuania & Kaunas & 150 & $12 / 86-6 / 87 ; 2 / 92-5 / 93$ & $87 ; 92$ \\
\hline New Zealand & Auckland & 299 & $1 / 93-3 / 94$ & 4/91-9/91 \\
\hline \multirow[t]{2}{*}{ Poland } & $\begin{array}{l}\text { Tarnobrzeg } \\
\text { Voivodship }\end{array}$ & 199 & $6 / 83-11 / 84 ; 5 / 87-11 / 88 ; 6 / 92-7 / 93$ & $1 / 86-5 / 86 ; 8 / 87-12 / 88 ; 92-93$ \\
\hline & Warsaw & 206 & $12 / 83-1 / 85 ; 1 / 88-1 / 89 ; 1 / 93-12 / 93$ & $86 ; 88 ; 93$ \\
\hline \multirow[t]{2}{*}{ Russia } & Moscow & 312 & $2 / 84-10 / 86 ; 2 / 88-1 / 89 ; 1 / 92-3 / 95$ & $86 ; 89 ; 92-93$ \\
\hline & Novosibirsk & 232 & $5 / 85-3 / 86 ; 5 / 88-4 / 89 ; 5 / 94-6 / 95$ & $86 ; 88-89 ; 93$ \\
\hline Spain & Catalonia & 388 & $4 / 86-7 / 88 ; 10 / 90-5 / 92 ; 6 / 94-5 / 96$ & $4 / 86-12 / 87 ; 90-92 ; 94$ \\
\hline \multirow[t]{2}{*}{ Sweden } & Gothenburg & 153 & $2 / 85-11 / 86 ; 2 / 90-5 / 91$ & $4 / 86-6 / 87 ; 91$ \\
\hline & Northern Sweden & 194 & $1 / 86-4 / 86 ; 1 / 90-4 / 90 ; 1 / 94-4 / 94$ & $11 / 86-6 / 87 ; 90 ; 94$ \\
\hline Switzerland* & Switzerland & 407 & $10 / 84-5 / 86 ; 10 / 88-4 / 90 ; 10 / 92-6 / 93$ & $86 ; 90 ; 7 / 92-12 / 93$ \\
\hline \multirow[t]{2}{*}{ UK } & Belfast & 157 & $10 / 83-9 / 84 ; 9 / 86-12 / 87 ; 10 / 91-12 / 92$ & $85 ; 88 ; 91-92$ \\
\hline & Glasgow & 131 & $2 / 86-7 / 86 ; 1 / 92-9 / 92 ; 2 / 95-10 / 95$ & $86 ; 92 ; 94$ \\
\hline USA & Stanford & 98 & $5 / 79-5 / 80 ; 5 / 85-6 / 86 ; 6 / 89-6 / 90$ & $81 ; 1 / 85-8 / 86 ; 89-90$ \\
\hline Yugoslavia & Novi Sad & 115 & $9 / 88-4 / 89 ; 9 / 94-2 / 95$ & $88-89 ; 94-95$ \\
\hline
\end{tabular}

coronary event records for most of the study period. Several centres collected ACC data continuously from the beginning to the end of the study. Others collected ACC data for a fixed period at the beginning of the study but after 1989 almost all centres collected these data continuously. Full details of the methods used in the event and acute coronary care registration are given in the MONICA manual and in the quality assessment reports (Quality assessment of coronary event registration data in the WHO MONICA Project. (January 1999). URL: www.ktl.fi/publications/monica/coreqa/ coreqa.htm, URN: NBN:fi-fe 19991072; Quality assessment of acute coronary care data in the WHO MONICA Project. URL: www.ktl.fi/publications/monica/accqa/accqa.htm, URN: NBN:fi-fe 19991081).

In all study populations two risk factor surveys were carried out near the beginning and at the end of the period of event monitoring. In most populations there was a third survey in the middle of the study period. Random samples of the general population (independent of coronary events) were selected from the best available sampling frames and were generally stratified by sex and 10 year age groups. Self reported cigarette smoking was obtained from participants in the risk factor surveys using a standard questionnaire on history of smoking.

\section{Quality assurance}

Quality assurance was an integral part of the WHO MONICA project. The internal consistency of the data was checked continuously at the MONICA data centre. In case of inconsistencies the centres were asked to verify the data. Test case series were circulated periodically, and quality assessment reports were produced periodically. The quality assessment reports are available at the MONICA WWW pages.

\section{Data analyses}

Smoking status was obtained for all patients who experienced non-fatal MI events, and smoking status in the referent population was obtained from the population surveys making this a case based study. ${ }^{15}$ Records with missing information on smoking were excluded from the analyses.

Only non-fatal MIs were considered in the analyses since data on smoking status were often missing for fatal events. Smoking status for each person was coded as current smoker or non-smoker. Current smoking was defined as any tobacco smoking on a daily basis within three months of the onset of the event. Data on past smoking were not collected in the ACC records.

From the survey data the smoking status of each participant was categorised as current daily cigarette smoker or non-smoker. In the survey questionnaire items about pipe and cigar smoking did not specifically ask about daily smoking but were included in the definition of a smoker to achieve comparability with the ACC data. In should be noted therefore that the definition of current smoker for survey participants was slightly different to the definition used for cases, which was any daily smoking in the past three months. It is possible therefore that some people who would have been classified as current smokers under the case definition were included as non-smokers among the controls. However, in the MONICA database we were able to ascertain whether subjects in the control population had quit smoking in the previous six months, and only $1 \%$ of the population had. It is reasonable to assume that only half of these quit in the three 


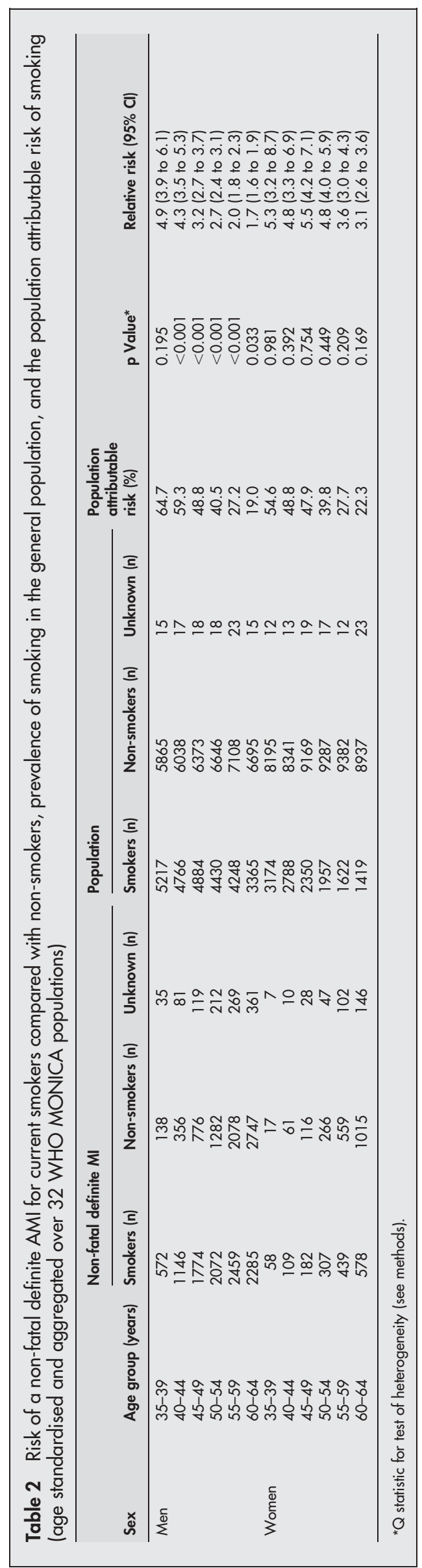

months before the survey and therefore it is unlikely that the difference definitions led to any significant increase in the estimates of relative risk.

The period in which information on smoking status was collected for coronary events varied between centres, but most of the 32 centres involved in this analysis contributed data from the middle of the 1980s to the middle of the 1990s.

\section{Statistical analysis}

Data were analysed separately for men and women and for each five year age group from 35-39 years to 60-64 years. The age standardised prevalence of smoking in each centre was estimated by the direct method using the world standard population weights of $6,6,6,5,4$ and 4 for the five year age groups from 35-39 years to 60-64 years. ${ }^{16}$

The relative risk of MI for current smokers compared with non-smokers was estimated using the random effects model proposed by DerSimonian and Laird, ${ }^{17}$ and tests of heterogeneity were conducted using the Q statistic with the mean value obtained by the Mantel-Haenszel method.

The proportion of non-fatal definite MIs that occurred as a result of exposure to smoking was estimated using the attributable fraction (AF) as described in Rothman and Greenland $^{18}: \quad \mathrm{AF}=[\mathrm{P} \times(\mathrm{RR}-1)] /[\mathrm{P} \times(\mathrm{RR}-1)+1], \quad$ where $\mathrm{P}=$ prevalence of smoking in the general population, and $\mathrm{RR}=$ relative risk of non-fatal definite $\mathrm{MI}$ in the population.

We examined the issue of missing data among cases and non-response rates among controls using graphical techniques and sensitivity analyses. Scatter plots and correlation coefficients were used to test for an association between the percentage of missing data among cases and prevalence of smoking among cases as well as the association between non-response rates and the prevalence of smoking among controls. Forest plots were used to look for an association between centre specific estimates of relative risk and potential sources of bias such as non-response rates, missing data, and prevalence of smoking. Sensitivity analyses were conducted by assuming all cases with missing data were smokers and secondly by assuming all cases with missing data were non-smokers. Similarly sensitivity analyses were conducted assuming that all non-responders to the population surveys were current smokers and then assuming they were non-smokers.

\section{RESULTS}

In the risk factor surveys the proportion of missing data on smoking was only $0-1 \%$; however, response rates varied considerably (range 50-90\%). In the ACC data for non-fatal definite MIs, information on smoking was fairly complete: the median amount of missing data for men was 3.5\% (range $1-36 \%$ ), for women $7.5 \%$ (range 0-36\%). Centres in Poland, Russia, Denmark, and the Czech Republic had high levels of missing information on smoking (15-36\%) for people with MI, but excluding these centres from the analysis made little difference to the results.

The age standardised prevalence of current smoking (excluding records with missing information on smoking) from the risk factor surveys varied from 18\% (New ZealandAuckland) to $65 \%$ (China-Beijing) in men and from $4 \%$ (Russia-Novosibirsk and Lithuania-Kaunas) to $44 \%$ (Denmark-Glostrup and Scotland-Glasgow) in women. The age standardised prevalence of current smoking in people with non-fatal MIs, obtained from the ACC data (excluding records with missing information on smoking), varied from $52 \%$ (Lithuania-Kaunas) to $84 \%$ (China-Beijing) in men and from 4\% (Russia-Novosibirsk) to 85\% (Denmark-Glostrop) in women. People who had a non-fatal MI were far more likely to be current smokers than people in the general community (figs 1 and 2). 


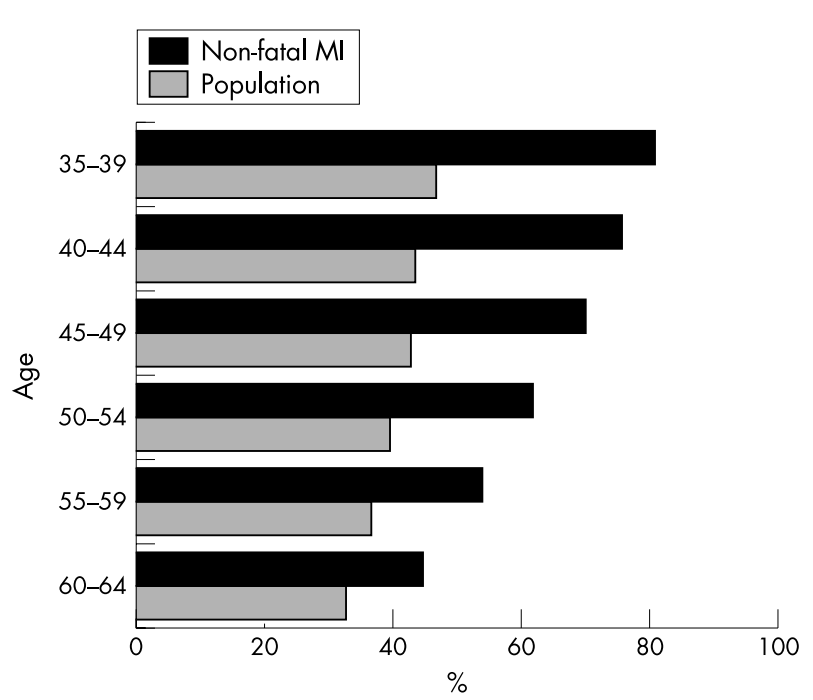

Figure 1 Prevalence of smoking in MONICA populations in non-fatal $\mathrm{Ml}$ events and in the population. Men aged 35-64 years. Records with missing data on smoking were excluded.

The risk of a non-fatal MI in current smokers was notably higher than the risk in non-smokers. In men, the relative risk ranged from 4.9 (95\% confidence interval (CI) 3.9 to 6.1 ) in the age group $35-39$ years to 1.7 (95\% CI 1.6 to 1.9 ) in the age group 60-64 years, and in women from 5.3 (95\% CI 3.2 to 8.7 ) to 3.1 (95\% CI 2.6 to 3.6 ), correspondingly (table 2 ). In the age group 35-39 years, approximately $65 \%$ of non-fatal MIs among men and 55\% among women could be attributed to smoking (table 2).

The sensitivity analysis produced predictable results. When all cases with missing data were assumed to be current smokers the relative risk estimates increase by approximately 0.3 for men and 0.4 for women but maintaining the same gradient across age groups. Similarly, the same gradient was maintained when all non-responders to the population surveys were assumed to be current smokers, although the impact on the estimates of relative risk was greater. For the youngest to oldest age groups, the relative risk estimates for men were 3.0, 2.6, 2.0, 1.6, 1.2, and 1.0, respectively. Except for the estimate in the oldest age group all estimates were significantly different from unity. For women the estimates of relative risk were $2.9,2.4,2.6,2.0,1.3$, and 1.0 and again all but the 1.0 were significant.

There was significant heterogeneity in the risk estimates within most age and sex groups. However, forest plots showed that non-response rates, percentage of missing data, and the prevalence of smoking were not associated with the estimates of relative risk.

\section{DISCUSSION}

The data from this large population based study confirmed the high prevalence of smoking in young MI patients (about $80 \%$ of men and women aged 35-39 years were smokers), and the very substantially increased risk of MI in young smokers, compared with non-smokers. In men and women aged 35-39 years, the risk of MI for those who smoked was five times higher than the risk for those who did not smoke. About $50 \%$ of MIs in men and women younger than 50 years were attributable to smoking and therefore potentially preventable. These findings for non-fatal definite MI events are in line with the observations on non-fatal events in the large case-control study in which the survivors of ISIS-3 and ISIS-4 studies (international studies of infarct survival) were cases. ${ }^{9}$ That study showed that the risk of non-fatal MI was

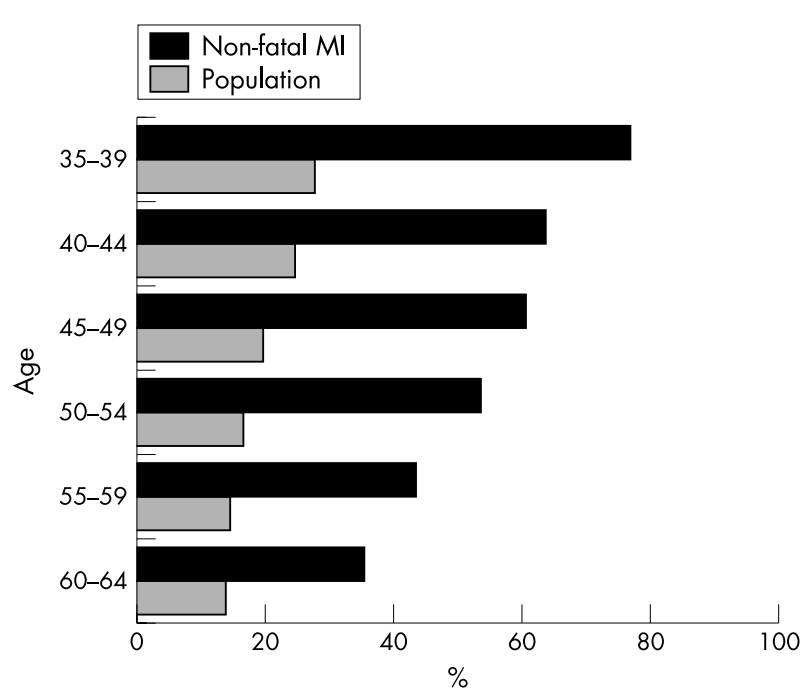

Figure 2 Prevalence of smoking in MONICA populations in non-fatal $\mathrm{Ml}$ events and in the population. Women aged 35-64 years. Records with missing data on smoking were excluded.

five times higher in smokers than non-smokers in the age group 30-49 years. In the British male doctors cohort study reported by Doll and Peto, ${ }^{19}$ the risk of CHD death in heavy smokers was 15 times higher than in non-smokers in the age group $<45$ years and three times higher in the age group $45-$ 54 years during 20 years follow up.

The data on MI occurring below the age 35 were sparse. The risk in the young (below 35 years) could therefore not be assessed reliably.

In this study, it was not possible to obtain complete data on smoking for people who died, and therefore only data for cases with non-fatal MI were used. This might lead to spurious association if smokers were protected from dying, as several clinical trials that include only hospitalised cases have indicated (for example, Barbash et $a^{20}$ ). However, sudden death is more common in smokers, compared with nonsmokers, ${ }^{21}$ and population based studies show that the risk of death during an acute event (including out-of-hospital and hospital deaths) is similar for smokers and non-smokers. ${ }^{22}{ }^{23}$ Thus, it is reasonable to assume that the risk of non-fatal events associated with smoking is representative of the risk of all events.

We explored only the risk of current smoking, since it was not possible to distinguish between never and past smokers among people who had a non-fatal MI. Since the risk of MI decreases quite rapidly after quitting smoking, ${ }^{24}$ the bias caused by this misclassification is likely to be small, especially in the young age group. In the British doctors' cohort total mortality was essentially the same in those who stopped smoking before the age of 35 as in non-smokers, but not subsequently. ${ }^{2}$ This indicates that the current study may underestimate the risk in older age groups. On the other hand, survey non-respondents may more often be smokers, causing an underestimation of smoking prevalence in the population and thus inflating the risk estimates. However, in our sensitivity analysis the gradient of risk was maintained and even if all non-responders were current smokers, which is extremely unlikely, the risk of MI among smokers was still statistically significant and biologically important in all but the oldest age group.

The relative risks for women were higher than for men in this study, particularly for the older age groups. One possible interpretation of this finding is that women are more sensitive to smoking than men, an issue of recent 


\section{What this paper adds}

Several case-control studies and case series have revealed a high prevalence of smoking in young myocardial infarction (MI) patients. Large scale, population based studies examining the true impact of current smoking on the occurrence of $\mathrm{Ml}$ in young age have, however, not been available thus far.

This large study documents the very high prevalence of current smoking in young Ml patients. It also documents that current smoking is the single most important factor behind an acute $\mathrm{Ml}$ in young patients. Current smoking is the sole or substantial contributory factor in at least $60 \%$ of acute Mls in the age group 35-39 years. Thus, every effort should be put to use to make young people realise the true and imminent risks of smoking to prevent them to start smoking, and to help those already caught to quit smoking.

controversy. ${ }^{25}$ Another possible explanation, which is more consistent with the age related trend in relative risk for men, is that in the absence of high levels of other risk factors for coronary disease smoking is the main determinant of risk. ${ }^{26}$

It is possible that the interaction between smoking and other factors-for example, hereditary coagulation defects ${ }^{7}$ may be particularly important in the occurrence of MI in young people. Many of these other factors may not be easily treatable. Indeed, smoking cessation programmes will probably be the mainstay of prevention available for such patients.

In conclusion, our data indicate that $50 \%$ of non-fatal MIs in men and women younger than 50 years (even more in younger age groups) would be preventable if smoking cessation programmes were successful. Smoking cessation would prevent excess mortality from a host of other diseases as well. ${ }^{2}$ There is a continuing need for public health programmes and anti-smoking campaigns targeted at young people to keep them healthy, and specifically from our results, also to prevent the particular tragedy of heart attack at a young age.

\section{ACKNOWLEDGEMENTS}

We thank the internal MONICA reviewers Stephen Fortmann, Kjell Asplund, and Andrzej Pajak for their comments on an earlier version of the manuscript.

The MONICA Centres were funded predominantly by regional and national governments, research councils, and research charities. Coordination is the responsibility of the World Health Organization (WHO), assisted by local fund raising for congresses and workshops. WHO also support the MONICA Data Centre (MDC) in Helsinki. Not covered by this general description is the ongoing generous support of the MDC by the National Public Health Institute of Finland, and a contribution to WHO from the National Heart, Lung, and Blood Institute, National Institutes of Health, Bethesda, Maryland, USA for support of the MDC and the Quality Control Centre for Event Registration in Dundee. The completion of the MONICA Project is generously assisted through a Concerted Action Grant from the European Community. Likewise appreciated are grants from ASTRA Hässle AB, Sweden, Hoechst AG, Germany, Hoffmann-La Roche AG, Switzerland, the Institut de Recherches Internationales Servier (IRIS), France, and Merck \& Co Inc, New Jersey, USA, to support data analysis and preparation of publications.

\section{Authors' affiliations}

M S Mähönen, K A Kuulasmaa, Department of Epidemiology and Health Promotion (MONICA Data Centre), KTL-National Public Health Institute, Helsinki, Finland

P McElduff, The Medical School, The University of Manchester, Manchester, UK

A J Dobson, School of Population Health, Faculty of Health Sciences, University of Queensland, Herston, Australia
A E Evans, Department of Epidemiology and Public Health, Queens University of Belfast, Belfast, UK

*See appendix for sites and key personnel of the WHO MONICA Project

\section{APPENDIX}

\section{SITES AND KEY PERSONNEL OF CONTRIBUTING MONICA CENTRES \\ Australia}

University of Western Australia, Nedlands: MST Hobbs ${ }^{1}, \mathrm{~K}$ Jamrozik $^{5}$, RW Parsons, C Spencer, PL Thompson;

University of Newcastle, Newcastle: A Dobson ${ }^{1}$, H Alexander, R Heller, P Colley, P McElduff

\section{Belgium}

Ghent State University, Ghent: G De Backer ${ }^{1}$, S De Henauw, D de Bacquer, F van Onsem;

Free University of Brussels, Brussels: M Kornitzer ${ }^{1}$, L Berghmans, L Bara, P de Smet, M Lannoy,R Desqueve, I Beriot, M Candeur

\section{Canada}

Dalhousie University, Halifax, Nova Scotia: HK Wolf ${ }^{1}$, RD Gregor5 , BR Mackenzie, PM Rautaharju, IR Bata

\section{China}

Beijing Heart, Lung and Blood Vessel Research Institute, Beijing: Wu Zhaosu' ${ }^{1}$, Wu Yingkai ${ }^{2}$, Yao Chonghua, Zhao Dong

\section{Czech Republic}

Institute for Clinical and Experimental Medicine, Prague: $\mathrm{Z}$ Škodová ${ }^{1}$, Z Píša, L Berka, Z Hejl, P Vojtišek, R Emrová, Z Cicha, M Hoke, J Pikhartová, K Hrdlicková, E Wiesner

\section{Denmark}

Centre of Preventive Medicine (The Glostrup Population Studies) Copenhagen University: M Schroll ${ }^{1}$, M Kirchhoff, A Sjoel, KK Thomsen, T Joergensen, M Madsen

\section{Finland}

National Public Health Institute, Helsinki: J Tuomilehto ${ }^{1}, \mathrm{P}$ Puska $^{2}$, H Korhonen, M Arstila, P Immonen-Räihä, E Kaarsalo, M Ketonen, S Lehto, H Miettinen, H Mustaniemi, M Niemelä, P Palomäki, K Pyörälä, M Romo, V Salomaa, J Torppa, T Vuorenmaa

\section{France}

National Institute of Health and Medical Research (INSERM U258) Paris: P Ducimetiere ${ }^{3}$, JL Richard ${ }^{4}$, A Bingham, T Lang;

National Institute of Health and Medical Research, Toulouse: J. Ferrieres ${ }^{1}$, JP Cambou ${ }^{2}$, JB Ruidavets, P Marqués-Vidal, MP Branchu, P Rodier, C Saulet;

Department of Epidemiology and Public Health - Faculty of Medicine, Strasbourg: D Arveiler ${ }^{1}$, P Schaffer $^{1}$, A Facello, E Marine Barjoan, E Uettwiller, D Jacgues, C Veron, V Meyer, M Velten, B Haas, N Lamamy, A Wagner, F Pierau;

Department of Epidemiology and Public Health, INSERM U508, Institut Pasteur and Medical University of Lille: $\mathrm{P}$ Amouyel $^{1}$, M Montaye-Faivre ${ }^{1}$, J-L Salomez ${ }^{2}$, S Beauchant, C Graux, B Lemaire, N Marecaux, C Steclebout, D Cottel, MC Nuttens $^{2}$

\section{Germany}

Bremen Institute for Prevention Research and Social Medicine, Bremen: E Greiser ${ }^{1}$, B Herman ${ }^{2}$, G Stüdemann;

GSF-Institute for Epidemiology, Munich and Institute for Epidemiology and Social Medicine, University of Münster: U 
Keil $^{1}$, J Stieber, A Döring, H Löwel, M Lewis, A Hörmann, J Gostomzyk, HD Bolte;

Centre for Epidemiology and Health Research, Berlin: W Barth $^{1}$, L Heinemann ${ }^{1}$, E Classen, D Quietzsch, S Brasche, S Böthig, G Voigt;

Department of Clinical and Social Medicine of the University Medical Clinic, Heidelberg: E Nüssel ${ }^{1}$, E OstörLamm $^{5}$, R Scheidt, W Morgenstern, M Stadler, M Ganowa

\section{Iceland}

Heart Preventive Clinic, Reykjavik: N Sigfusson ${ }^{1}$, II Gudmundsdottir, I Stefansdottir, TH Thorsteinsson, H Sigvaldason

Italy

National Institute of Health, Rome: A Menotti ${ }^{3}$, S Giampaoli, A Verdecchia;

Research Centre on Chronic Degenerative Diseases of the University of Milan: GC Cesana ${ }^{1}$, M Ferrario ${ }^{1}$, M T Gussoni, G De Vito, R Sega, F Valagussa, F Achilli;

Institute of Cardiology, Regional Hospital, Udine: D Vanuzzo $^{1}$, GA Feruglio ${ }^{2}$, L Pilotto, G Zanata, M Scarpa, G B Cignacco, R Marini, M Spanghero, G Zilio

\section{Lithuania}

Kaunas Medical Academy, Institute of Cardiology: J Bluzhas $^{1}$, S Domarkiene, A Tamosiunas, V Grinius, R Grazuleviciene, Z Petrokiene, D Rasteniene, D Rastenyte, R Radisauskas, D Sidlauskiene, R Reklaitiene

\section{New Zealand}

University of Auckland: R Beaglehole ${ }^{1}$, RT Jackson, AW Stewart, W Bingley

\section{Poland}

Collegium Medicum, Jagiellonian University in Kraków: A Pajak $^{1}$, J Sznajd ${ }^{2}$, E Kawalec, R Topor-Madry, E Baczynska, A Celinski, H Czarnecka, A Hebda, B Idzior-Walus, E Kozek, M Magdon, M Malczewska-Malec, M Malecki, A Markiewicz, P Misiowiec, R Mizera, R Morawski, W Rostworowski, I Trznadel-Morawska, U Zeman, A Zarnecki;

National Institute of Cardiology, Warsaw, Department of Cardiovascular Epidemiology and Prevention: S Rywik ${ }^{1}, \mathrm{G}$ Broda $^{5}$, M Polakowska, A Pytlak, H Wagrowska, P Kurjata, W Kupsc

\section{Russian Federation}

National Research Centre for Preventive Medicine, Moscow: R Oganov, V Konstantinov, A Britov, N Popova, V Naumova, G Zhukovsky ${ }^{1}$, T Varlamova ${ }^{2}$;

Institute of Internal Medicine, Novosibirsk: Yu P Nikitin ${ }^{1}$, S Malyutina, I Shalaurova, V Gafarov, G Simonova

\section{Spain}

Department of Health and Social Security, Barcelona: S Sans ${ }^{1}$ L Balañá, G Paluzie, I Balaguer-Vintró ${ }^{2}$, A Puigdefàbregas

\section{Sweden}

Sahlgrenska University Hospital at Ostra, Section of Preventive Cardiology, Göteborg: L Wilhelmsen ${ }^{1}$, P Harmsen, A Rosengren, S Johansson, M Falkman, G Lappas; Department of Internal Medicine, Kalix Lasarett, Kalix: $T$ Messner $^{1}$, F Huhtasaari ${ }^{2}$, V Lundberg, E Jägare Westerberg, B Wikström, S Boström;

Umeå University Hospital, Department of Medicine: K Asplund $^{1}$, P O Wester ${ }^{2}$, B Stegmayr, M Peltonen

\section{Switzerland}

Institute of Social and Preventive Medicine, University of Lausanne: M Rickenbach, V Wietlisbach, D Hausser, F Paccaud;

Institute of Social and Preventive Medicine, University of Zurich: F Gutzwiller ${ }^{1}$;

Department of Social Affairs, Cantonal Health Office of Ticino: F Barazzoni, F Mainieri, G Domenighetti.

\section{UK}

The Queen's University of Belfast, Northern Ireland: AE Evans ${ }^{1}$, EE McCrum, T Falconer, Z M Mathewson, E E McCrum, A Hall, T Falconer, E L McIlmoyle;

University of Dundee, Scotland: H Tunstall-Pedoe ${ }^{1}$, WCS Smith $^{6}$, R Tavendale, C Brown, M Shewry, M-K Hannah;

Royal Infirmary, Glasgow, Scotland: C Morrison ${ }^{5}$, G Watt ${ }^{6}$, W Leslie, B Fitzpatrick

\section{USA}

Stanford Center for Research in Disease Prevention, Stanford University, California: SP Fortmann ${ }^{1}$, A Varady, M Hull

\section{Yugoslavia}

Novi Sad Health Centre: M Planojevic ${ }^{1}$, D Jakovljevic ${ }^{2}$, Z.Solak, M.Zikic, T Dapik, M Solak, D Stojsic, M Zikic

\section{MONICA MANAGEMENT CENTRE}

World Health Organization, Geneva: S Mendis ${ }^{7}$, I Martin ${ }^{8}$, I Gyarfas $^{8}, \mathrm{Z} \mathrm{Pisa}^{8}$, SRA Dodu ${ }^{8}$, S Böthig 8 , A Price, MJ Watson, M Hill

\section{MONICA DATA CENTRE}

National Public Health Institute, Helsinki, Finland: K Kuulasmaa $^{7}$, J Tuomilehto ${ }^{8}$, H Tolonen, E Ruokokoski, AM Rajakangas, A Molarius, V Moltchanov, M Mähönen, Z Cepaitis

\section{MONICA QUALITY CONTROL CENTRE FOR ECG CODING}

Hungarian Institute of Cardiology, Budapest, Hungary: P Ofner $^{7}$, A Madai ${ }^{8}$

\section{MONICA QUALITY CONTROL CENTRE FOR EVENT REGISTRATION}

University of Dundee, Scotland: Hugh Tunstall-Pedoe (responsible officer), Kristin Barrett, Colin Brown

\section{MONICA STEERING COMMITTEE}

K Asplund (Chair), P Amouyel (Publications Coordinator), A Pajak, H Tunstall-Pedoe (Rapporteur), S Mendis, K Kuulasmaa, A Shatchkute (WHO, Copenhagen), A Evans. Consultant: A Dobson

Previous Steering Committee Members: M Ferrario, M.Hobbs, S Sans, F Gutzwiller, R Beaglehole, SP Fortmann, A Menotti, P Puska, SL Rywik, U Keil, and former Chiefs of CVD/HQ, Geneva (listed above), V Zaitsev (WHO, Copenhagen), J Tuomilehto. Former Consultants: Z Pisa, OD Williams (Birmingham, Alabama, USA), MJ Karvonen, (Helsinki, Finland), RJ Prineas, (Minneapolis, USA); M Feinleib, (Bethesda, USA); FH Epstein, (Zürich, Switzerland)

Key: ${ }^{1}$ Principal Investigator; ${ }^{2}$ Former Principal Investigator; ${ }^{3}$ Country Co-ordinator; ${ }^{4}$ Former Country Co-ordinator; ${ }^{5} \mathrm{Co}-$ Principal Investigator; ${ }^{6}$ Former Co-Principal Investigator; ${ }^{7}$ Responsible Officer; ${ }^{8}$ Former Responsible Officer

\section{REFERENCES}

1 US Department of Health and Human Services. The health consequences of smoking: cardiovascular disease. A report of the Surgeon General, 1983. 
Rockville, Maryland: Public Health Service, Office on Smoking and Health, 1983 (DHHS Publication No (PHS) 84-50204.).

2 Doll R, Peto R, Wheatley K, et al. Mortality in relation to smoking: 40 years' observations on male British doctors. BMJ 1994;30:901-11.

3 Newby DE, Wright RA, Labinjoh C, et al. Endothelial dysfunction, impaired endogenous fibrinolysis, and cigarrette smoking. A mechanism for arterial thrombosis and myocardial infarction. Circulation 1999;99:1411-5.

4 Caralis DG, Deligonul U, Kern MJ, et al. Smoking is a risk factor for coronary spasms in young women. Circulation 1992;85:905-9.

5 Celermajer DS, Sorensen KE, Georgapoulos D, et al. Cigarette smoking is associated with dose-related and potentially reversible impairment of endothelium-dependent dilation in healthy young adults. Circulation 1993;88:2149-55.

6 Smith CJ, Fischer TH. Particulate and vapor phase constituents of cigarette mainstream smoke and risk of myocardial infarction. Atherosclerosis 2001;158:257-67.

7 Doggen CJM, Cats VM, Bertina RM, et al. Interaction of coagulation defects and cardiovascular risk factors. Increased risk of myocardial infarction associated with factor $V$ Leiden or prothrombin 20219A. Circulation 1998;97:1037-41.

8 Barbash GI, White HD, Modan M, et al. Acute myocardial infarction in the young - the role of smoking. The investigators of the international tissue plasminogen activator/streptokinase mortality trial. Eur Heart J 1995;16:313-6.

9 Parish S, Collins R, Youngman L, et al, for the International Studies of Infarct Survival (ISIS) collaborators. Cigarette smoking, tar yields and non-fatal myocardial infarction: 14,000 UK cases and 32,000 controls. BMJ 1995:311:471-7.

10 Tunstall-Pedoe H, for the WHO MONICA Project Principal Investigators. The World Health Organization MONICA project (monitoring trends and determinants in cardiovascular disease): a major international collaboration J Clin Epidemiol 1988:41:105-14.

11 Tunstall-Pedoe H, Kuulasmaa K, Amouyel P, et al, for the WHO MONICA Project. Myocardial infarction and coronary deaths in the World Health Organization MONICA project. Registration procedures, event rates and case fatality in 38 populations from 21 countries in 4 continents. Circulation 1994:90:583-612.

12 Tunstall-Pedoe $\mathrm{H}$, Kuulasmaa $\mathrm{K}$, Mähönen $\mathrm{M}$, et al, for the WHO MONICA Project. Contribution of trends in survival and coronary-event rates to changes in coronary heart disease mortality: 10 year results from 37 WHO MONICA project populations. Lancet 1999;353:1547-57.

13 Kuulasmaa K, Tunstall-Pedoe H, Dobson A, et al, for the WHO MONICA Project. Estimation of contribution of changes in classic risk factors to trends in coronary-event rates across the WHO MONICA project populations. Lancet 2000;355:675-87

14 Tunstall-Pedoe H, Vanuzzo D, Hobbs M, Mähönen M, Cepaitis Z, Kuulasmaa K, Keil U, for the WHO MONICA Project. Estimation of contribution of changes in coronary care to improving survival, event rates, and coronary heart disease mortality across the WHO MONICA project populations. Lancet 2000;355:688-700

15 Miettinen OS. The 'case-control' study: valid selection of subjects. J Chron Dis 1985;38:543-8.

16 Waterhouse J, Muir CS, Correa P, et al. Cancer incidence in five continents. Lyon: IARC, 1976:456.

17 DerSimonian R, Laird N. Meta-analysis in clinical trials. Controlled Clinical Trials 1986;7:177-88

18 Rothman KJ, Greenland S, eds. Modern epidemiology, 2nd ed. Philadelphia: Lippincott Williams\&Wilkins, 1998.

19 Doll R, Peto R. Mortality in relation to smoking: 20 years' observations on male British doctors. BMJ 1976;ii: 1525-36.

20 Barbash GI, White HD, Modan M, et al. Significance of smoking in patients receiving thrombolytic therapy. Experience gleaned from the international tissue plasminogen activator/streptokinase mortality trial. Circulation 1993;87:53-8.

21 Escobedo LG, Caspersen CJ. Risk factors for sudden coronary death in the United States. Epidemiology 1997;8:175-80.

22 McElduff P, Dobson AJ. Case fatality after an acute cardiac event: the effect of smoking and alcohol consumption. J Clin Epidemiol 2001;54:58-67.

23 Sonke GS, Stewart AW, Beaglehole R, et al. Comparison of case-fatality in smokers and non-smokers after acute cardiac event. BMJ 1997;315:992-3.

24 McElduff $P$, Dobson A, Beaglehole $R$, et al. Rapid reduction in coronary risk for those who quit cigarette smoking. Aust N Z J Public Health 1998;22:787-91.

25 Prescott E. Commentary: tobacco-related disease: a gender difference? Int J Epidemiol 2001;30:793-4.

26 Tang JL, Dickinson JA. Studying relative risk is not enough. BMJ 1998;317:1017.

\section{The lighter side}

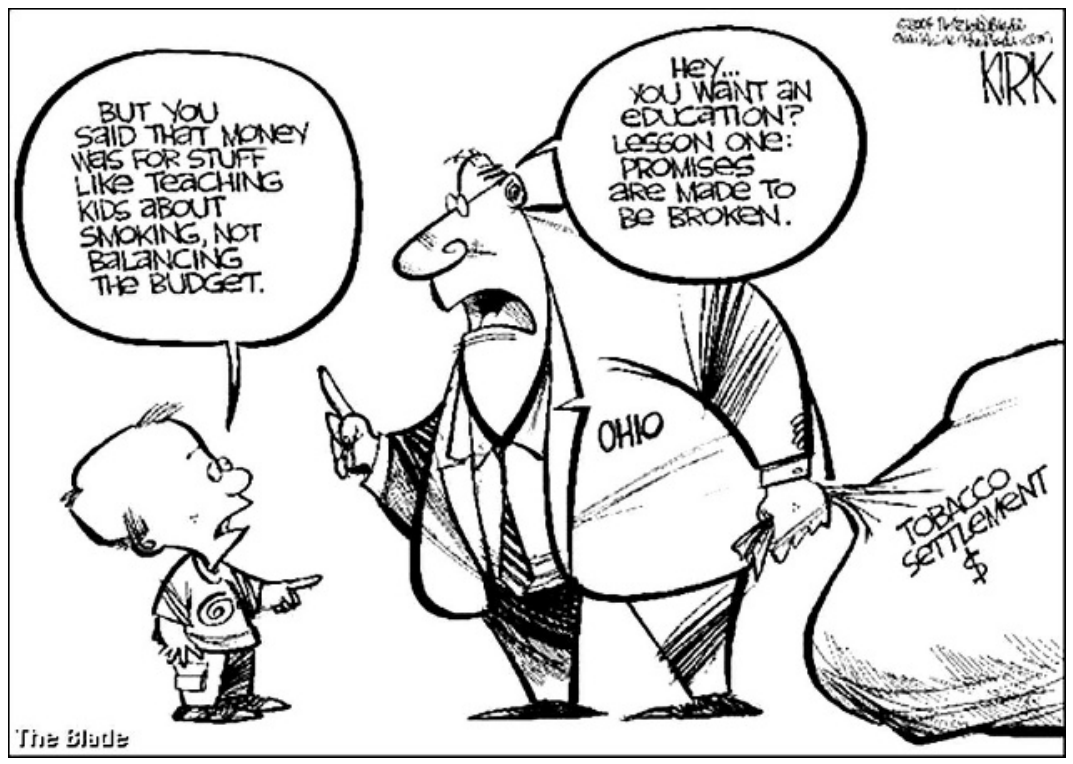

Ohio is one of dozens of US states to have US MSA (Master Settlement Agreement) funds for general revenues rather than for tobacco control measures.

(c) Kirk. Reprinted with permission from the Toledo Blade, 2004. 